\title{
Strongyloides ratti Antigenic Components Recognized by IgE Antibodies in Immunoblotting as an Additional Tool for Improving the Immunodiagnosis in Human Strongyloidiasis
}

\author{
Rosângela Maria Rodrigues ${ }^{++}$, Mônica Camargo Sopelete, \\ Deise Aparecida de Oliveira Silva, Jair Pereira Cunha-Júnior, Ernesto Akio Taketomi, \\ Julia Maria Costa-Cruz ${ }^{+}$
}

Departamento de Imunologia, Microbiologia e Parasitologia, Instituto de Ciências Biomédicas, Universidade Federal de Uberlândia, Av. Pará 1720, 38400-902 Uberlândia, MG, Brasil

\begin{abstract}
IgE antibody response in human strongyloidiasis was evaluated by enzyme-linked immunosorbent assay (ELISA) and immunoblotting (IB) using Strongyloides ratti saline extract as heterologous antigen. A total of 50 serum samples of patients who were shedding S. stercoralis larvae in feces (group I, copropositive), 38 of patients with other intestinal parasites (group II), and 38 of subjects with negative results in three parasitologic assays (group III, copronegative) were analyzed. Levels of IgE anti-Strongyloides expressed in ELISA Index (EI) were significantly higher in patients of group I (1.32) than in group II (0.51) and group III (0.81), with positivity rates of 54\%, $0 \%$, and $10.5 \%$, respectively. Fifteen S. ratti antigenic components were recognized in IB-IgE by sera of group I, with frequency ranging from $8 \%$ to $46 \%$. In group II, only two antigenic bands $(101,81 \mathrm{kDa})$ were detected in a frequency of $10 \%$ and no reactivity was found in group III. Sera with EI values $>1.5$ recognized five from 13 specific antigenic bands $(70,63,61,44,7 \mathrm{kDa})$. It can be concluded that these five antigenic components recognized by IB-IgE using S. ratti antigen might be employed as an additional tool for improving the immunodiagnosis in human strongyloidiasis.
\end{abstract}

Key words: strongyloidiasis - Strongyloides ratti - IgE - immunoblotting - ELISA

Strongyloides stercoralis is an intestinal nematode with worldwide distribution, predominantly in tropical and subtropical countries, and sporadically in temperate regions. Strongyloidiasis is a severe disease, but it can be clinically inapparent in the majority of patients with infection restricted to the gastrointestinal tract. Nevertheless, the systemic invasion of the parasite by its larval stage leads to a fatal hyperinfection syndrome or disseminated strongyloidiasis, particularly in immunocompromised subjects like patients with cancer, organ transplant recipients, acquired immunodeficiency syndrome (AIDS), and patients upon corticoids and other immunosuppressive therapy (Ferreira et al. 1999, Siddiqui \& Berk 2001, Oliveira et al. 2002).

Previous studies have shown that circulating $\operatorname{IgE}$ antibodies and eosinophils play an important role in the immune response to helminths (Meeusen \& Balic 2000). High levels of specific IgE are usually demonstrated in immunocompetent patients with strongyloidiasis whereas lower

Financial support: Conselho Nacional de Desenvolvimento Científico e Tecnológico, Coordenação de Aperfeiçoamento de Pessoal de Nível Superior, and Universidade Federal de Uberlândia, MG, Brasil

+Corresponding author. Fax: +55-34-3218.2333. E-mail: costacruz@ufu.br

${ }^{++}$Graduate student of Applied Immunology and Parasitology, Federal University of Uberlândia

Received 14 July 2003

Accepted 18 December 2003 levels are found in the disseminated disease and immunosuppressive conditions (Atkins et al. 1997, Vercelli et al. 1998).

IgE anti-S. stercoralis antibodies have been detected by radioallergosorbent test (RAST), enzyme-linked immunosorbent assay (ELISA), and immunoblotting (IB) (McRury et al. 1986, Conway et al. 1993, Sato et al. 1995, Atkins et al. 1997). However, one of the most important limitations for immunodiagnosis in strongyloidiasis is the difficulty for obtaining $S$. stercoralis filariform larvae. Thus, studies have been conduced using heterologous antigen of filariform larvae from Strongyloides ratti and Strongyloides venezuelensis in the development of serological methods (Grove \& Blair 1981, Costa-Cruz et al. 1997, Machado et al. 2001). The aim of this study was to evaluate $\operatorname{IgE}$ antibody response in human strongyloidiasis by immunoblotting using $S$. ratti saline extract as heterologous antigen and to compare it with ELISA-IgE results.

\section{MATERIALS AND METHODS}

Serum samples - A total of 126 serum samples of individuals divided into three groups according to the coproparasitologic results obtained from the Ferrioli (1961), Lutz (1919), and Ritchie (1948) methods was analyzed. Group I consisted of 50 serum samples of patients from the Clinical Hospital, Federal University of Uberlândia and the Municipal Health Service, Uberlândia, state of Minas Gerais, Brazil, who were shedding S. stercoralis larvae in the feces (copropositive); group II consisted of 38 sera of patients with other intestinal parasites, such as Ascaris lumbricoides (10 cases); Enterobius vermicularis (4 cases); hookworm (5 cases); Taenia sp. (3 cases); Trichu- 
ris trichiura ( 2 cases); Giardia lamblia (12 cases); Entamoeba histolytica (2 cases); and group III comprised 38 serum samples of healthy individuals with negative results in three fecal samples (copronegative) and with no history of Strongyloides infection. In addition, subjects of groups II and III were non-reactive to Strongyloides as determined by ELISA-IgG. The Ethics Committee in Research of the Federal University of Uberlândia approved this study.

Parasites - S. ratti larvae were obtained from the feces of experimentally infected rats (Rattus rattus). The fecal samples were mixed with an equal part of finely ground wood charcoal, moistened with water, spread in an uniform layer on Petri dishes and incubated at $25^{\circ} \mathrm{C}$ for 5 days. Filariform larvae were then harvested according to the Ferrioli (1961) method, concentrated by centrifugation for $5 \mathrm{~min}$ at $1000 \mathrm{~g}$ and stored at $-20^{\circ} \mathrm{C}$ until being used in the heterologous antigen preparation.

Heterologous antigen - S. ratti filariform larvae $(500,000)$ were resuspended in $1 \mathrm{ml}$ of $0.01 \mathrm{M}$ phosphate buffered saline (PBS) pH 7.2 containing 2 mM EGTA, 2 $\mathrm{mM}$ EDTA and $0.3 \mathrm{mg} / \mathrm{ml}$ of protease inhibitors (Boehering Mannheim, Germany). For antigenic extraction, larvae on ice bath were disrupted using tissue homogenizer (Omnith International, US) with 5 cycles for 5 min and then submitted to 8 ultra-sound cycles for $20 \mathrm{~s}$ at $40 \mathrm{kHz}$ (Thorton, Inspec Eletrônica, São Paulo, Brazil). After overnight incubation at $4^{\circ} \mathrm{C}$ under continuous agitation, the suspension was centrifuged at $3000 \mathrm{~g}$ for $30 \mathrm{~min}$ at $4^{\circ} \mathrm{C}$ and the supernatant (saline extract) was analyzed for protein content by the Lowry et al. (1951) method and stored at $-20^{\circ} \mathrm{C}$ until being used in ELISA and IB.

ELISA-IgE - Strongyloides-specific IgE antibodies were measured in serum samples of groups I, II, and III by indirect ELISA using heterologous antigen as described by Costa-Cruz et al. (2003). Preliminary experiments were carried out in order to determine the optimal conditions for ELISA-IgE, through block titration of the reagents (antigen, sera, and conjugate). High-binding microtiter plates (Costar, Sigma, US) were coated with $10 \mu \mathrm{g} / \mathrm{ml}$ of S. ratti saline extract in $0.06 \mathrm{M}$ carbonate-bicarbonate buffer, $\mathrm{pH}$ 9.6 and incubated overnight at $4{ }^{\circ} \mathrm{C}$. Plates were washed three times for 5 min with PBS containing $0.05 \%$ Tween 20 (PBS-T) and blocked with PBS-T plus $1 \%$ bovine serum albumin (PBS-T-BSA) for $1 \mathrm{~h}$ at room temperature (RT). Subsequent steps were carried out using PBS-T-BSA as diluent and washings in PBS-T were done between the steps of the reaction. The plates were incubated with serum samples diluted at $1: 2$ in duplicate for $2 \mathrm{~h}$ at $37^{\circ} \mathrm{C}$. Subsequently, biotinylated goat anti-human IgE (Kirkegaard \& Perry Laboratories Inc, Baltimore, MD, US) was added (1:500) and incubated for $1 \mathrm{~h}$ at $37^{\circ} \mathrm{C}$, and then streptavidin-peroxidase conjugate (Sigma) diluted at 1:500 was incubated for $30 \mathrm{~min}$ at RT. The assay was developed by adding the enzyme substrate consisting of 0.01 M 2,2'azino-bis-3 ethyl-benzthiazoline sulfonic acid (ABTS) (Sigma) and $0.03 \% \mathrm{H}_{2} \mathrm{O}_{2}$, and the absorbance was read at $405 \mathrm{~nm}$ in a plate reader (Titertek Multiskan Plus, Flow Laboratories, US). Three positive control sera obtained from patients who were shedding S. stercoralis larvae in the feces and three negative control sera from healthy subjects were included in each assay. The results were arbitrarily expressed as ELISA Index (EI) and determined as follows: $\mathrm{EI}=$ absorbance of test sample/cut off, where cut off was calculated as the mean absorbance of negative control sera plus five standard deviations. Values of EI > 1.0 were considered as positive. Additionally, EI values were arbitrarily ranked into four reactivity classes for comparison: $($ class 0$) \leq 1.0 ;($ class 1$)>1.0 \leq 1.5 ;($ class 2$)>$ $1.5 \leq 5.0$ and (class 3$)>5.0$.

$I B-I g E-S$. ratti saline extract $(100 \mu \mathrm{g}$ of final protein content) was diluted (v/v) in sample buffer (31 mM Tris pH 8.8, 2\% SDS, 11 mM EGTA, $20 \%$ sucrose, $0.25 \%$ bromophenol blue) and boiled for $3 \mathrm{~min}$ at $100^{\circ} \mathrm{C}$. The antigen extract was then separated by sodium dodecyl sulfate-polyacrylamide gel electrophoresis (SDS-PAGE) using a $14 \%$ resolving gel under reducing and non-reducing conditions (Hoefer Pharmacia Biotech Inc, San Francisco, US) according to the method of Laemmli (1970) and subsequently silver-stained (Friedman 1982). After electrophoretic separation, protein fractions were transferred to nitrocellulose membranes ( $0.45 \mu \mathrm{m}$; Sigma) using a semidry transfer system (Multiphor II Electrophoresis Unit, Pharmacia LKB, Uppsala, Sweden) as described by Towbin et al. (1979). Nitrocellulose membranes were divided into 3 $\mathrm{mm}$-strips and blocked with 5\% skim milk (SM) in $0.02 \mathrm{M}$ Tris buffered saline plus $0.05 \%$ Tween 20 (TBS-T) for $6 \mathrm{~h}$ at RT, and subsequently incubated with serum samples diluted at 1:2 in TBS-T- $1 \%$ SM for $24 \mathrm{~h}$ at $4^{\circ} \mathrm{C}$ under continuous agitation. The strips were washed six times with TBS-T and then incubated with biotinylated goat antihuman IgE (Kirkegaard \& Perry Lab. Inc.) at 1:500 in TBS$\mathrm{T}-1 \% \mathrm{SM}$ for $20 \mathrm{~h}$ at $4^{\circ} \mathrm{C}$. After washing procedures, an amplification system (streptavidin-biotinylated peroxidase complex; Dako, Denmark) diluted at 1:500 in TBS-T-1\% $\mathrm{SM}$ was added and incubated for $1 \mathrm{~h}$ at RT. After final washings, the strips were developed using a chemiluminescence system (ECL, Amersham Pharmacia Biotech, Buckinhamshire, England), following the manufacturer instructions. For negative controls, reactions were carried out in the absence of primary or secondary antibodies, i.e., substituting test sera with TBS-T-1\% SM.

Statistical analysis - Statistical analysis consisted of determinations of geometric means for specific IgE to Strongyloides and the differences between the means obtained in the different groups were analyzed by the Student $t$ test. Frequencies of positivity in ELISA-IgE and $S$. ratti antigenic components recognized in IB-IgE among the different groups were compared using the analysis between two proportions by Z statistics. Differences were considered as statistically significant when $\mathrm{p}<0.05$.

\section{RESULTS}

Levels of IgE anti-Strongyloides expressed in EI measured in serum samples of groups I, II, and III are shown in Fig. 1. The geometric mean of specific IgE levels in patients of group I (1.32) was significantly higher than in group II $(0.51 ; \mathrm{p}=0.0001)$ and group III $(0.81 ; \mathrm{p}=0.0002)$, with positivity rates of $54 \%(27 / 50), 0 \%(0 / 38)$ and $10.5 \%$ (4/38), respectively.

The electrophoretic profile in SDS-PAGE and reactivity of IgE antibodies to $S$. ratti by IB in sera of groups I, II, 


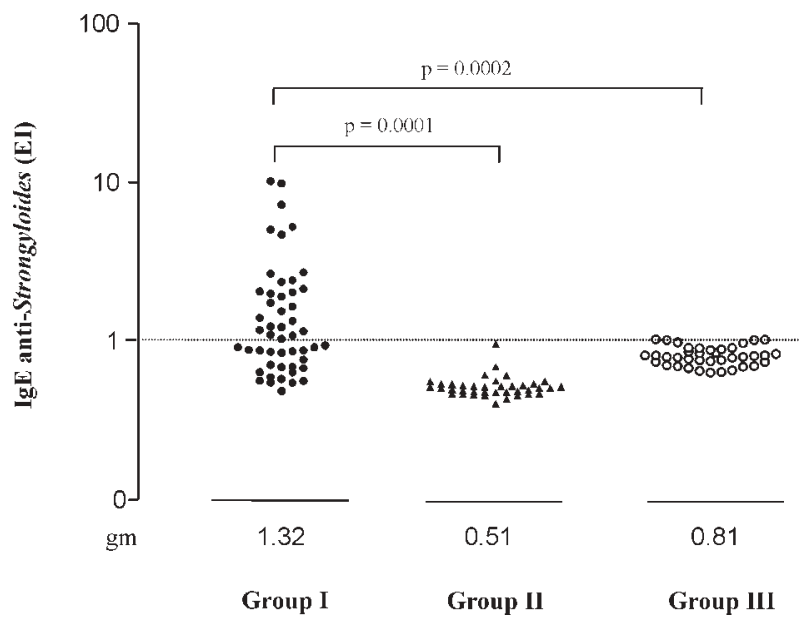

Fig. 1: levels of IgE anti-Strongyloides expressed in ELISA Index (EI) measured in 50 serum samples of patients with strongyloidiasis (group I, copropositive), 38 serum sample of patients with other intestinal parasites (group II), and 38 serum samples of healthy subjects (group III, copronegative) using $S$. ratti saline extract as heterologous antigen in ELISA-IgE. The dashed line represents the cut off value; gm: geometric mean

and III are illustrated in Fig. 2. Protein components of $S$. ratti extract, with relative molecular masses ranging from 101 to $7 \mathrm{kDa}$, were visualized predominantly in group I. Fifteen antigenic components (101, 81, 70, 63, 61, 57, 54, $44,39,36,33,28,19,15,7 \mathrm{kDa})$ with frequency ranging from 8 to $46 \%$ were recognized in IB-IgE by sera of group I, whereas only two antigenic bands $(101,81 \mathrm{kDa})$ were detected in a frequency of $10 \%$ in group II (Fig. 3A) and no reactivity was found in group III. The frequency of the antigenic band of $101 \mathrm{kDa}$ detected in the group I (46\%)

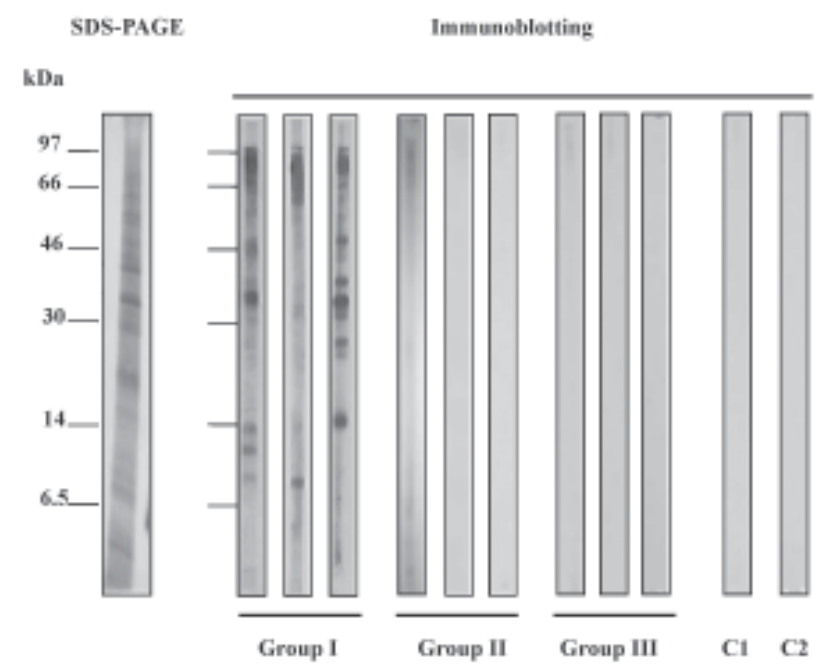

Fig. 2: electrophoretic profile (SDS-PAGE) and reactivity of $\mathrm{IgE}$ antibodies to Strongyloides ratti antigenic components (IB-IgE) in three representative sera of patients with strongyloidiasis (group I, copropositive), patients with other intestinal parasites (group II), and healthy subjects (group III, copronegative). C1 and C2 correspond to the internal controls of the reaction in the absence of primary antibody and in the absence of primary plus secondary antibodies, respectively. Molecular mass values (kDa) are shown on the left. was significantly higher than in groups II (10\%) and III $(0 \%)(\mathrm{p}<0.05)$. However, no difference was found when comparing the frequency of the $81 \mathrm{kDa}$ band in the group I $(36 \%)$ and group II (10\%). These two antigenic components $(101,81 \mathrm{kDa})$ were non-specific, since they showed $10 \%$ cross-reactivity with samples from patients with other parasitic diseases and samples with an EI $\leq 1.5$. Thus, these two bands were not considered as specific immunodominant bands.

The reactivity classes of specific IgE to Strongyloides obtained in ELISA-IgE were analyzed with regard to the number of $S$. ratti antigenic components recognized in IB-IgE by 50 sera of patients of group I, 10 sera of group II and 10 sera of group III. In group I, 2 (8.7\%) of 23 sera presenting class $0(\mathrm{EI} \leq 1.0$, negative specific $\mathrm{IgE})$ recognized only one antigenic band (101 kDa); out of 9 sera with class $1(\mathrm{EI}>1.0 \leq 1.5)$, only one $(11.1 \%)$ recognized one band $(101 \mathrm{kDa})$ and $2(22.2 \%)$ recognized from 2 to 5 bands; $8(61.5 \%)$ of 13 sera presenting class 2 (EI $>1.5 \leq$ 5.0) recognized from 6 to 9 bands; and all of 5 sera with class 3 (EI > 5.0) recognized more than 6 antigenic bands. In group II, only one (10\%) of 10 sera with negative specific IgE $(\mathrm{EI} \leq 1.0)$ recognized two bands $(101,81 \mathrm{kDa})$, although they were weakly stained when compared to their reactivity in group I. No reactivity was found in group III.

Considering as immunodominant antigenic components those that were recognized by sera in a frequency equal or more than $50 \%, 13$ antigenic bands $(70,63,61,57$, $54,44,39,36,33,28,19,15,7 \mathrm{kDa})$ were detected by sera from class $3(E I>5.0)$ whereas five of these bands $(70,63$, $61,44,7 \mathrm{kDa}$ ) were detected by sera from class 2 (EI $>1.5$ $\leq 5.0$ ) in the group I. No immunodominant antigenic component was noticed in negative $\operatorname{IgE}$ sera $(\mathrm{EI} \leq 1.0)$ while two of these immunodominant bands $(61,44 \mathrm{kDa})$ were recognized by a single serum of class 1 (EI $>1.0 \leq 1.5)$ (Fig. 3B). In addition, all sera from class 3 and $77 \%$ of sera from class 2 recognized two to five of the specific immunodominant bands.

\section{DISCUSSION}

Regarding the difficulty for obtaining sufficient amount of $S$. stercoralis filariform larvae, it has become necessary the standardization and utilization of heterologous antigens from $S$. ratti, which can be used as reliable source of antigens for immunodiagnosis in human strongyloidiasis, thus replacing $S$. stercoralis antigen (Grove \& Blair 1981, Rossi et al. 1993). In this study, patients with strongyloidiasis (group I) had significantly higher levels and positivity rates of specific IgE to $S$. ratti as compared to the patients with other intestinal parasites (group II) and healthy subjects (group III). Despite the presence of only 4/38 seropositive samples in the group III, these were detected in borderline cut off values and this positivity was not statistically significant in relation to the group II.

Immunoblotting has been largely utilized to characterize Strongyloides protein fractions recognized by different antibody classes (Conway et al. 1993, Uparanukraw et al. 1999). In the present study, out of 15 antigenic fractions recognized by IgE in sera of patients with strongy- 
A

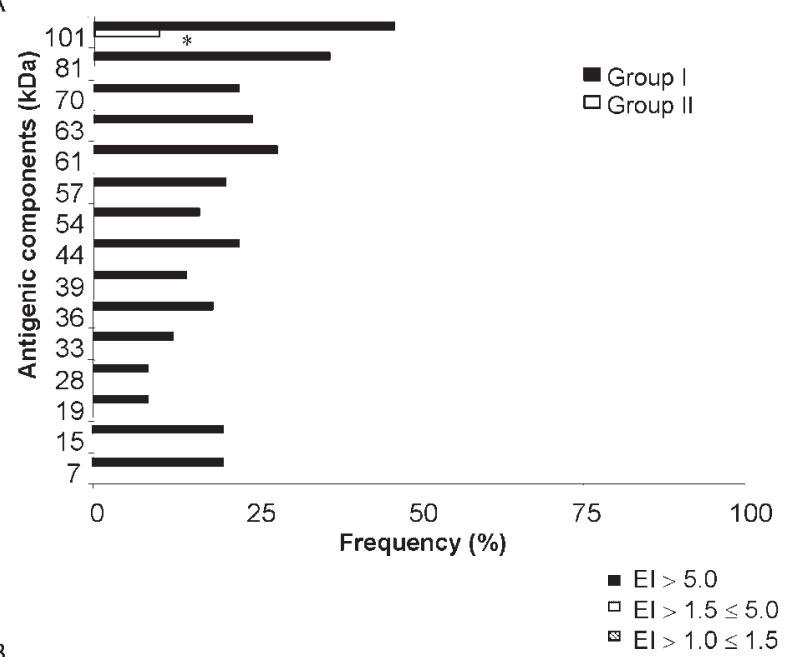

B

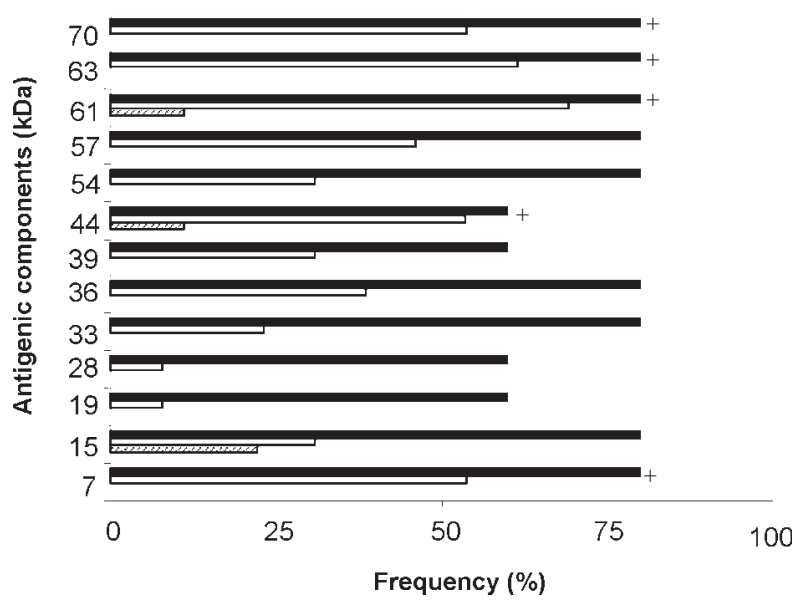

Fig. 3 A: frequency (\%) of Strongyloides ratti antigenic components $(\mathrm{kDa})$ recognized in IB-IgE by 50 serum samples of patients with strongyloidiasis (group I, copropositive) and 10 sera of patients with other intestinal parasites (group II); *p $<0.05$; B: frequency $(\%)$ of $13 \mathrm{~S}$. ratti antigenic components $(\mathrm{kDa})$ recognized in IB-IgE only by sera from patients with strongyloidiasis (group I, copropositive) according to the different reactivity classes (EI > $1.0 \leq 1.5$, EI $>1.5 \leq 5.0$ and $\mathrm{EI}>5.0$ ) determined in ELISA-IgE to S. ratti; EI: ELISA Index; +: immunodominant bands

loidiasis, three $(44,36,33 \mathrm{kDa})$ had already been described in the literature (Atkins et al. 1999). Considering the different extracts used and the intrinsic variability of the reactions, it can be presumed that the bands of 28 and 57 $\mathrm{kDa}$ found in this study might correspond to bands of 29 and $56 \mathrm{kDa}$, respectively, described by Atkins et al. (1999) when using S. stercoralis homologous antigen for the detection of specific IgE.

Different reactivity classes determined in ELISA-IgE to $S$. ratti showed diverse antigenic profiles in IB-IgE. Accordingly, sera from patients of group I presenting IgE reactivity classes 2 or 3 (EI >1.5) recognized a higher number of different $S$. ratti antigenic fractions in IB-IgE. Theses results are in agreement with the findings of Hagan (1993) and Atkins et al. (1997) who showed that patients with high levels of specific IgE might be presenting an initial phase of $S$. stercoralis infection. In contrast, patients presenting low levels of specific IgE associated with a low frequency of antigenic components detected in IB-IgE might reflect cases of asymptomatic chronic infection. Additionally, several studies have demonstrated a predominance of specific IgG4 antibodies in S. stercoralis chronic infections and the important role of such antibodies as modulators in the IgE-mediated immune response (Ishizaka 1982, Atkins et al. 1999).

In group II, only two antigenic fractions $(101,81 \mathrm{kDa})$ were recognized by a single serum sample and such bands were weakly stained when compared to their reactivity in group I. Therefore, since this serum sample was negative $\mathrm{IgE}(\mathrm{EI} \leq 1.0)$, there is a real possibility of cross-reactivity with other intestinal parasites.

When analyzing the frequency of $S$. ratti antigenic components in IB-IgE according to different reactivity classes in ELISA-IgE to $S$. ratti in sera of group I, a broad spectrum of antigenic fractions was visualized. Thus, sera with EI > 5.0 recognized 13 immunodominant bands (70, $63,61,57,54,44,36,39,33,28,19,15,7 \mathrm{kDa})$ with frequency equal or more than $50 \%$, while sera presenting EI $>1.5 \leq 5.0$ recognized only five from these immunodominant fractions $(70,63,61,44,7 \mathrm{kDa})$. In our recent report (Silva et al. 2003) we have shown that in IB-IgG, 11 antigenic immunodominant bands were recognized by at least $25 \%$ of sera from patients with strongyloidiasis. In this study (IB-IgE), 5 different and highly specific antigenic bands were recognized by equal or more than $50 \%$ of sera from patients with EI > 1.5.

Taken together, it can be concluded that the five antigenic components recognized by IB-IgE using $S$. ratti antigen might be employed as an additional tool for improving the immunodiagnosis in human strongyloidiasis.

\section{ACKNOWLEDGMENTS}

To Dr Dulcinéa Maria Barbosa Campos for supplying Strongyloides ratti larvae; to Maria do Rosário de Fátima Gonçalves-Pires and Ivanildes Solange da Costa Barcelos for their suggestions and technical helpful.

\section{REFERENCES}

Atkins NS, Conway DJ, Lindo JF, Bailey JW, Bundy DA 1999. L3 antigen-specific antibody isotype responses in human strongyloidiasis: correlations with larval output. Parasite Immunol 21: 517-526.

Atkins NS, Lindo JF, Lee MG, Conway DJ, Bailey JW, Robison RD, Bundy DAP 1997. Humoral responses in human strongyloidiasis: correlations with infection chronicity. Trans R Soc Trop Med Hyg 91: 609-613.

Conway DJ, Atkins NS, Lillywhite JE, Bailey JW, Robinson RD, Lindo JF, Bundy DA, Bianco AE 1993. Immunodiagnosis of Strongyloides stercoralis infection: a method for increasing the specificity of the indirect ELISA. Trans $R$ Soc Trop Med Hyg 87: 173-176.

Costa-Cruz JM, Bullamah CB, Gonçalves-Pires MRF, Campos DMB, Vieira MA 1997. Cryo-microtome sections of coproculture larvae of Strongyloides stercoralis and Strongyloides ratti as antigen sources for the immunodiagnosis of human strongyloidiasis. Rev Inst Med Trop São Paulo 39: 313-317.

Costa-Cruz JM, Madalena J, Silva DAO, Sopelete MC, Campos DMB, Taketomi EA 2003. Heterologous antigen extracts in 
ELISA for the detection of human IgE anti-Strongyloides stercoralis. Rev Inst Med Trop São Paulo 45: 265-268.

Ferreira MS, Nishioka SA, Borges AS, Costa-Cruz JM, Rossin JR, Rocha A, Silvestre MTA, Nunes-Araújo FRF 1999. Strongyloidiasis and infection due to human immunodeficiency virus: 25 cases at a Brazilian teaching hospital, including seven cases of hyperinfection syndrome. Clin Inf Dis 28: 154-155.

Ferrioli F 1961. Condições que influem na extração de larvas do Strongyloides stercoralis das fezes pelo método de LossBaermann modificado (Técnica do Pires). Rev Inst Med Trop São Paulo 3: 51-60.

Friedman RD 1982. Comparison of four different silver-staining techniques for salivary protein detection in alkaline polyacrylamide gels. Annal Biochem 126: 346-349.

Grove DI, Blair AJ 1981. Diagnosis of human strongyloidiasis by immunofluorescence, using Strongyloides ratti and $S$. stercoralis larvae. Am J Trop Med Hyg 30: 344-349.

Hagan P 1993. IgE and protective immunity to helminth infections. Parasite Immunol 15: 1-4.

Ishizaka T 1982. IgE and mechanisms of IgE-mediated hypersensitivity. Ann Allergy 48: 313-319.

Laemmli UK 1970. Cleavage of structural proteins during the assembly of the head of bacteriophage T4. Nature 227: 680-685.

Lowry OH, Rosebrough NJ, Farr AL, Randall RJ 1951. Protein measurement with the folin phenol reagent. J Biol Chem 29: $265-275$

Lutz AV 1919. Schistosoma mansoni e a schistossomose, segundo observações feitas no Brasil. Mem Inst Oswaldo Cruz 11: 121-125.

Machado ER, Ueta MT, Gonçalves-Pires MRF, de Oliveira JB, Faccioli LH, Costa-Cruz JM 2001. Diagnosis of human strongyloidiasis using particulate antigen of two strains of Strongyloides venezuelensis in indirect immunofluorescence antibody test. Exp Parasitol 99: 52-55.

McRury J, de Messias IT, Walzer PD, Huitger T, Genta RM 1986. Specific IgE responses in human strongyloidiasis. Clin Exp Immunol 65: 631- 638.

Meeusen EN, Balic A 2000. Do eosinophils have a role in the killing of helminth parasites? Parasitol Today 16: 95-101.

Oliveira LCM, Ribeiro CT, Mendes DM, Oliveira TC, CostaCruz JM 2002. Frequency of Strongyloides stercoralis infection in alcoholics. Mem Inst Osvaldo Cruz 97: 119-121.

Ritchie LS 1948. An ether sedimentation technique for routine stool examination. Bull US Army Med Dept 8: 326-334.

Rossi CL, Takahashi EE, Partel CD, Teodoro LGVL, da Silva LJ 1993. Total serum IgE and parasite-specific IgG and IgA antibodies in human strongyloidiasis. Rev Inst Med Trop São Paulo 35: 361-365.

Sato Y, Kobayashi J, Shiroma Y 1995. Serodiagnosis of strongyloidiasis. The application and significance. Rev Inst Med Trop São Paulo 37: 35-41.

Siddiqui AA, Berk SL 2001. Diagnosis of Strongyloides stercoralis infection. Clin Inf Dis 33: 1040-1047.

Silva LP, Barcelos ISC, Passos-Lima AB, Espindola FS, Campos DMB, Costa-Cruz JM 2003. Western blotting using Strongyloides ratti antigen for the detection of IgG antibodies as confirmatory test in human strongyloidiasis. Mem Inst Oswaldo Cruz 98: 687-691.

Towbin H, Staehelin T, Gordon J 1979. Electrophoretic transfer of proteins from polyacrylamide gels to nitrocellulose sheets: procedure and some applications. Proc Natl Acad Sci 76: 4350-4354.

Uparanukraw P, Phongsri S, Morakote N 1999. Fluctuations of larval excretion in Strongyloides stercoralis infection. Am J Trop Med Hyg 60: 967-973.

Vercelli D, De Monte L, Monticelli S, Di Bartolo C, Agresti A 1998. To E or not to E? Can an IL-4 induced B cell choose between IgE and IgG4? Int Arch Allergy Immunol 116: 1-4. 